\title{
What determines the shape of the probability weighting function?
}

\section{Working Paper}

Author(s):

Fehr-Duda, Helga; Schürer, Marc; Schubert, Renate

Publication date:

2006-08

Permanent link:

https://doi.org/10.3929/ethz-a-005229431

Rights / license:

In Copyright - Non-Commercial Use Permitted

Originally published in:

Economics Working Paper Series 06/54 


\title{
CER-ETH - Center of Economic Research at ETH Zurich
}

\section{What Determines the Shape of the Probability Weighting Function?}

\author{
Helga Fehr-Duda \\ Marc Schürer \\ Renate Schubert \\ Working Paper 06/54 \\ August 2006
}

\section{Economics Working Paper Series}

\section{EIH}

Eidgenössische Technische Hochschule Zürich Swiss Federal Institute of Technology Zurich 


\title{
What Determines the Shape of the Probability
}

\section{Weighting Function?}

\author{
Helga Fehr-Duda** \\ Marc Schürer \\ Renate Schubert
}

\begin{abstract}
When valuing risky prospects, people typically overweight small probabilities and underweight medium and large probabilities, but there is vast heterogeneity in individual behavior. We explore the relationship between person-specific probability weights, estimated from investment decisions in a laboratory experiment, and personal characteristics. We find considerable interaction effects with gender. While women's probability weighting is strongly and significantly susceptible to mood states, men's is not. Moreover, we show that cheerful and optimistic people weight probabilities of investment gains more favorably than do pessimistic people. People who calculate expected payoffs are less prone to probability distortions than those who do not use a lottery's expected value as a decision criterion. None of the factors studied impact subjects' valuations of monetary outcomes.
\end{abstract}

KEY WORDS: Probability Weighting Function, Prospect Theory, Risk Aversion, Gender Differences

\footnotetext{
** Authors' affiliation: Institute of Economic Research, Swiss Federal Institute of Technology, Weinbergstrasse 35, CH-8092 Zurich. Please address all correspondence to fehr@wif.gess.ethz.ch
} 


\section{Introduction}

The canonical economic model of decision under risk, expected utility theory, assumes that the decision maker evaluates risky outcomes by weighting the utilities of the outcomes with their respective probabilities. This view has been severely challenged in past decades, however. A large number of alternative theories were introduced in the wake of experiments suggesting that people systematically violate the axioms of expected utility theory (for a review, see Starmer 2000). In particular, people do not weight utilities linearly with the corresponding probabilities, but tend to overestimate small probabilities while underestimating moderate and large probabilities. This phenomenon led Kahneman and Tversky (Kahneman and Tversky 1979, Tversky and Kahneman 1992) to incorporate a nonlinear probability weighting function as a core component in their prospect theory, a novel descriptive theory of decision under risk. They not only adopt the inverted S-shaped probability weighting function because it fits their data well, but also because the psychological principle of diminishing sensitivity justifies its use.

The inverted S-shaped probability function accounts for the empirically observed fourfold pattern of risk attitudes (Abdellaoui 2000, Fehr-Duda et al. in press, Tversky and Fox 1995, Wu and Gonzalez 1996 and 1998, among others). People are typically risk averse for gains occurring with large probabilities and for losses occurring with small probabilities, and, in contrast, risk-seeking for losses occurring with large probabilities and for gains occurring with small probabilities. Even though this pattern emerges for the majority of decision makers, individual behavior is quite heterogeneous. The principle of diminishing sensitivity is consistent with many different types of individual behavior - the probability weighting function may be more or less curved. Prospect theory is silent on the forces underlying the specific curvature of a person's probability weighting function.

The empirical literature does not provide much insight, either. So far, it has focused on the relationship between the shape of the probability weighting function and specific features of the decision situation. Tversky and Kahneman (1992) themselves conceded that their theory is unlikely to be accurate in detail. They surmised - and others have provided evidence - that the probability weights might be sensitive to the formulation of the prospects, as well as to the number, spacing, and level of outcomes (e.g. Camerer 1992, Etchart-Vincent 2004, Wu and Markle 2004). 
To our knowledge, the only study addressing gender-specific effects in probability weights with respect to investment decisions is addressed in Fehr-Duda et al. (in press). The authors find the women's median probability weighting function to be more curved than the men's, i.e. women are less sensitive to probability changes. The gender difference is particularly pronounced and significant for medium and large probabilities, where women underweight given probabilities much more strongly than do men.

The findings by Fehr-Duda et al. raise the following questions: Why do some people exhibit more curved probability weighting functions than others? And why are women less sensitive to probability changes than men? Does the gender difference disappear when other explanatory variables are included in the analysis? In this paper, we search for personal characteristics correlated with the individual variation in probability weights in the context of investment decisions. For this purpose, we regress estimated probability weights on a number of explanatory variables gained from an extensive questionnaire.

We select the explanatory variables for the following reasons. First, we explore some of the implications of the risk-as-feeling hypothesis (Loewenstein et al. 2001, Loewenstein and Lerner 2003). Whereas expected emotions have long been integrated into expected utility models (e.g. Walther 2001), economists have only recently acknowledged the role of immediate emotions, present at the moment of decision making. Loewenstein and Lerner distinguish between two different types of immediate emotions: anticipatory emotions and incidental emotions. Anticipatory feelings arise when thinking about the consequences of a decision and thus depend on specific features of the consequences and how these features interact with the decision maker's personality. Loewenstein and Lerner argue that anticipatory feelings are sensitive to the timing and vividness of outcomes, but relatively insensitive to probabilities. Moreover, anticipatory affective responses depend on the individual's perceived control over the environment. People who feel in control seem to be less vulnerable to anticipatory feelings. In this paper, we explore the relationship between the curvature of the probability weighting function and an individual's disposition towards feeling in control as measured by locus of control. The contrasting component of immediate emotions, incidental affect, is totally unrelated to the decision at hand and comprises lingering moods and emotions. If people are susceptible to incidental emotions at the moment of decision making, these emotions may influence their choices, i.e. risk preferences may depend on situational 
factors. We therefore explore the relationship between the curvature of the probability weighting function and background mood.

Second, there are two natural a priori hypotheses as to which variables might influence probability weighting: one pertains to personality, the other to the guidelines used in decision making. The personality trait we consider is cheerfulness. We would expect that people who judge themselves to be cheerful and optimistic to place a higher weight on probabilities of achieving gains, i.e. to actually behave more optimistically than do anxious and pessimistic people. Self-reported cheerfulness will therefore be one of the variables in our model explaining the shape of the probability weighting function. As far as the decision guideline is concerned, we would expect people who use a lottery's expected value as one criterion for reaching a decision to distort given probabilities to a lesser degree than those who do not consider expected payoffs. The expected value criterion is our final candidate for explaining the shape of the probability weighting function.

We present five main findings. First, the explanatory variables - background mood, locus of control, cheerfulness, and expected value criterion - do not affect the valuation of financial outcomes. The curvature of the value function is insensitive to the factors studied. This result implies that the explanatory variables directly influence subjects' relative risk aversion by their effects on probability weights. Second, we find that the explanatory variables have a strong gender-specific effect on probability weighting.

Third, probability weights are sensitive to incidental factors. Mood states have a significant and substantial effect on probability weights, albeit only for women. Women who are in a persistently good mood tend to underestimate probabilities of gains more strongly than do women in a bad persistent mood. This finding is consistent with the mood maintenance hypothesis (Isen and Labroo 2003) which postulates that a good mood is also at stake in risky decision making and that, therefore, people in a good mood tend to behave more cautiously than those in a neutral or bad mood. We also find that women weight probabilities relatively more optimistically, and are therefore relatively more risk-seeking, when their immediate mood deviates positively from their usual state of mood.

Fourth, we find a significant relationship between locus of control and probability weighting. Men who attribute outcomes to their efforts rather than to fate do not distort probabilities as 
strongly as men with an external locus of control. This finding is consistent with the view that internal people are less vulnerable to anticipatory feelings. Women with an internal locus of control, however, are relatively more pessimistic than external women.

Finally, we confirm that probability weights move in the direction they should theoretically move. We find that cheerful and optimistic people indeed weight probabilities more favorably, and are therefore relatively more risk seeking than are pessimistic and anxious people. With respect to the decision criterion, we find that men who use expected values as one guideline for decision making tend to distort stated probabilities less strongly, i.e. their probability weighting curves lie closer to linear weighting. Women, by their own account, do not use expected values as a guideline. These later results show that the estimation procedure is capable of picking up important determinants of the probability weighting function, which lends credibility to the other effects obtained.

The paper is structured as follows. We briefly describe our data and the estimation method employed in Section 2. In Section 3, we develop our hypotheses concerning the relationship between probability weights and the explanatory variables constructed from the questionnaire. The regression results are presented in Section 4. The discussion in Section 5 concludes the paper.

\section{Data and Method}

In order to explore the relationship between the curvature of the probability weighting function and subjects' personal characteristics, two types of estimations must be performed. First, individual probability weights need to be estimated from subjects' choices. At the second stage, these probability weights are regressed on a number of explanatory variables. Subjects' choices were observed in the course of a laboratory experiment with real monetary incentives (Fehr-Duda et al. in press). The explanatory variables were constructed from the questionnaire complementing the experiment.

Students of various faculties of the Swiss Federal Institute of Technology and the University of Zurich were recruited for an experiment which took place in the computer lab of the Institute of Empirical Research in Economics, University of Zurich, in June and August 2003. 
Subjects' certainty equivalents were elicited for 25 two-outcome winning gambles framed as investment decisions. Outcomes ranged from zero to 150 Swiss Francs ${ }^{1}$, with probabilities of $5,10,25,50,75,90$, and 95\%. After completing all their decisions subjects were presented with a questionnaire (see Appendix ${ }^{2}$ ), where they had to report on personality traits, background mood, and decision criteria used, as well as socioeconomic data. When the subjects had completed the questionnaire, one of their lottery choices was randomly selected for payment. Average actual payoffs exceeded the mean local hourly wage for student assistants by roughly $80 \%$, including a show-up fee of 10 Swiss Francs. The experimental sessions lasted about one hour in total.

In the following, we briefly describe the procedure used to estimate the individual probability weighting functions and value functions (for a complete description refer to Fehr-Duda et al. in press) and present the questionnaire data.

We applied the concepts of prospect theory (Tversky \& Kahneman 1992) for estimating probability weights. Regarding the functional form for the probability weighting function, Lattimore et al. (1992) propose the following two-parameter functional $\mathrm{w}$ of the probability $\mathrm{p}$ assigned to the respective prospects' best outcomes:

$$
\mathrm{w}(\mathrm{p})=\delta \mathrm{p}^{\gamma} /\left[\delta \mathrm{p}^{\gamma}+(1-\mathrm{p})^{\gamma}\right] ; \delta \geq 0, \gamma \geq 0,
$$

which has proven to account for individual heterogeneity well (Wu et al. in press). Parameter $\delta$ largely governs the elevation of the curve, while $\gamma$ largely determines its slope: the smaller the value of $\gamma$, the more S-shaped the $\mathrm{w}(\mathrm{p})$ curve, and the greater the value of $\delta$, the more elevated the curve, ceteris paribus. Linear weighting is characterized by $\gamma=\delta=1$.

The second component of prospect theory, the value function $\mathrm{v}$, is modeled as follows:

$$
\mathrm{v}(\mathrm{x})=\mathrm{x}^{\alpha} ; \alpha>0,
$$

with $\mathrm{x}$ representing the monetary outcomes.

Fehr-Duda et al. estimated the parameters $\alpha, \gamma$, and $\delta$ for each single individual using the maximum likelihood method based on the observed certainty equivalents for the 25 investment choices. As the estimated probability weights and the estimated curvature parameter of the value function are used as dependent variables in our subsequent regression

\footnotetext{
${ }^{1}$ At the time of the experiment, one Swiss Franc equaled about 0.80 U.S. Dollars.
} 
analysis, the parameter estimates need to differ significantly from zero to be meaningful. Therefore, all subjects with insignificant parameter estimates ${ }^{3}$ (roughly $20 \%$ of subjects) and those with missing questionnaire data were excluded from the analysis. This procedure left 69 subjects in total, 40 men and 29 women. The mean deviations of estimated probability weights from the stated probabilities are presented in Table 1. The data displays the familiar pattern. On average, small probabilities are overweighted, while medium and large probabilities are underweighted considerably. Women, on average, deviate more strongly from linear weighting. The mean estimated curvature parameters for the value functions lie in the vicinity of one, reflecting linearity of the value function for a considerable number of subjects.

\section{(insert Table 1)}

We now turn to the determinants of subjects' probability weights. The explanatory variables for the regression analysis are derived from the subjects' questionnaire responses. The factors we are most interested in comprise the following. The first set of variables is constructed to investigate the effects of immediate emotions on probability weighting. Emotions present at the moment of decision making may stem from lingering background mood and from anticipatory feelings associated with the expected consequences of the decision. We measure background mood with the subject's self-reported state of mood. The intensity of anticipatory feelings may depend, among other factors, on a person's perceived control over the environment, which is measured as a subject's locus of control. The second set of variables is geared towards the relationship between what people say about themselves and what they actually do. We explore whether optimistic and cheerful people actually assess probabilities more favorably and whether people who, by their own account, use expected payoffs as a guideline in decision making deviate less strongly from linear probability weighting. Summary statistics of the explanatory variables are displayed in Table 2. Socioeconomic information such as age, income, employment level, and major field of study, as well as knowledge of economics and experience in the domain of financial decisions (investment, insurance, and gambling) were included as controls.

\section{(insert Table 2)}

\footnotetext{
${ }^{2}$ The Appendix includes only those questions which are relevant to this paper. The full version of the questionnaire is available from the authors upon request.
} 
The variable for locus of control, LOCONTROL, is derived from Questions 2 and 3 in the Appendix. According to the internal/external distinction, locus of control measures an individual's perception of how much control she exerts over the events in her life. An internal person is convinced that the outcomes of her behavior are the results of her own endeavors whereas an external person attributes the outcomes to fate. In this study, an internal person is characterized by a high score on Question 2 ("Are you able to achieve your aims and to carry out your plans?") and a low one on Question 3 ("How often do you have the feeling that fate determines what happens to you?"). The opposite holds for an external person. The variable is measured on a 6-point scale; "absolutely" in Question 2 and "never" in Question 3 are encoded as " 5 ", the opposite ends of the scale are encoded as " 0 ".

We have two different constructs for mood state. Immediate Mood, IMMOOD, is measured on a 6-point scale (Question 9) and captures a person's state of mood on the day of the experiment relative to her usual state of mood. IMMOOD is assigned a high value (4 or 5) for better mood than usual, and a low value ( 0 or 1$)$ for one worse than usual. On average, subjects report feeling pretty much as usual. An index for the mood state in the month prior to the experiment, PERMOOD, is constructed from the average scores on questions 4 through 8 presented on a 6-point scale. Values may range from 0 to 5 . These questions relate to how a subject had generally been feeling, whether she had slept well ${ }^{4}$, and to what extent she had felt under stress and pressure in the month before the experiment took place. The higher the value of PERMOOD, the better the subject had been feeling during the said period.

Self-reported cheerfulness is measured as follows: Question 1 in the Appendix requests participants to rate the extent to which attributes apply to themselves on a four-point scale; "not true" is encoded as " 0 ", true is encoded as " 3 ". The variable CHEERFULNESS is the average score assigned to the following 6 items: cheerful, lucky beggar, content, pessimistic, optimistic, and anxious, with the scores for negative attributes adjusted accordingly. The higher the value of CHEERFULNESS, the more cheerful and optimistic the person characterizes herself.

\footnotetext{
${ }^{3}$ Applying the Bonferroni criterion to the pooled (male and female) data and the male data does not change our results. It could not be applied for the female data because of an insufficient number of observations.

${ }^{4}$ Recent work by Kahneman suggests that the quality of sleep is an important determinant for wellbeing.
} 
To capture the effects of calculating expected payoffs we constructed the dummy variable EXVALUE. Participants were asked to explain the criteria influencing their decisions briefly in Question 10. The answers to this open question were encoded in the following way. Some participants explicitly mentioned that they had calculated the lotteries' expected payoffs; some others described a procedure which closely resembled the calculation of the expected value. The dummy variable EXVALUE was assigned the value of 1 for subjects in these two categories; the variable was set to zero for everyone else.

We tested all these variables with respect to significant gender differences. Neither of the variables CHEERFULNESS, LOCONTROL, IMMOOD, nor PERMOOD exhibit gender differences (judged by a Mann-Whitney test). For instance, the mean values of LOCONTROL are 3.57 for women and 3.53 for men. Significantly more men than women use the expected value criterion, however. EXVALUE = 1 for 20 men, but only for 3 women (Mann-Whitney test significant at the $1 \%$-level).

\section{(insert Table 3)}

Significant partial correlations of the probability weights with the explanatory variables display a remarkable pattern (Table 3). The explanatory variables typically exhibit significant correlations only for a limited range of probabilities, and turn out to be significant only for medium and large probabilities for most of the variables. For self-reported cheerfulness, CHEERFULNESS, correlations are significant over the range of probabilities from $5 \%$ to $75 \%$. The fact that there is no constant relationship between probability weights and the variable in question over the total range of probabilities suggests that a regression model with constant coefficients for all levels of probability is not appropriate; instead, we chose to estimate the relationship between probability weights and explanatory variables separately for each level of probability. The following regression model consists of 7 equations corresponding to the levels of probability:

$$
\mathrm{w}\left(\mathrm{p}_{\mathrm{i}}\right)-\mathrm{p}_{\mathrm{i}}=\beta_{\mathrm{i} 0}+\beta_{\mathrm{i} 1} \mathrm{X}_{1}+\beta_{\mathrm{i} 2} \mathrm{X}_{2}+\ldots+\beta_{\mathrm{in}} \mathrm{X}_{\mathrm{n}}+\varepsilon_{\mathrm{i}}
$$

with $\mathrm{w}\left(\mathrm{p}_{\mathrm{i}}\right)$ the probability weights of $\mathrm{p}_{\mathrm{i}}$ estimated according to $(1), \mathrm{i}=1,2, \ldots, 7$, and $\mathrm{p}_{\mathrm{i}}$ being the level of probability; $X_{1}, \ldots, X_{n}$ the explanatory variables; and $\beta_{i j}, j=0, \ldots, n$ the parameters to be estimated. The vectors $\mathrm{w}\left(\mathrm{p}_{\mathrm{i}}\right), \varepsilon_{\mathrm{i}}$, and $\mathrm{X}_{\mathrm{j}}$ are of dimension $(\mathrm{Tx} 1), \mathrm{T}$ being the number of 
individuals. Zellner's seemingly unrelated regression method was employed, to account for the fact that the error terms $\varepsilon_{\mathrm{i}}$ may be correlated across equations ${ }^{5}$.

To check whether the explanatory variables also affect the valuation of outcomes, we estimated the following model by applying the robust regression technique:

$$
\alpha=\gamma_{0}+\gamma_{1} X_{1}+\gamma_{2} X_{2}+\ldots+\gamma_{n} X_{n}+\mu
$$

with $\alpha$ being the vector of estimated curvature parameters of the value function in (2), $\mathrm{X}_{1}, \ldots, \mathrm{X}_{\mathrm{n}}$ the explanatory variables; $\gamma_{\mathrm{j}}, \mathrm{j}=0, \ldots, \mathrm{n}$ the parameters to be estimated and $\mu$ the error term. All the vectors are of dimension (Tx1), with T representing the number of individuals. It turns out that none of the coefficients of the explanatory variables in equation (4) differs significantly from zero. This means that the valuation of outcomes is not sensitive to LOCONTROL, IMMOOD, PERMOOD, CHEERFULNESS, or EXVALUE. If we are able to detect a significant effect of one or more variables on the shape of the probability weighting function, this effect carries over directly to relative risk taking behavior.

\section{Hypotheses}

In order to discuss the relationship between the explanatory variables and the probability weights, Table 4 lists the potential combinations of the signs of the estimated coefficients in equation (2) and their resulting impact on the probability weighting curve.

Table 4: Potential Effects of an Explanatory Variable on the Probability Weighting

\section{Function}

\begin{tabular}{|l|ccc|}
\hline Probabilities $p$ & Small $p$ & Large $p$ & Probability weights \\
\hline Sign of coefficient & + & + & relatively more optimistic \\
& - & - & relatively more pessimistic \\
& + & - & less rational \\
& - & + & more rational \\
\hline
\end{tabular}

\footnotetext{
${ }^{5}$ This assumption was clearly confirmed by a Breusch-Pagan test.
} 
A positive regression coefficient indicates that the dependent variable moves with the explanatory variable. If probability weights $w(p)$ increase with a positive change in the explanatory variable over the whole range of probabilities, probabilities receive higher weights, i.e. the person overweights small probabilities of the best outcomes more strongly and underweights large probabilities of the best outcomes less strongly. She displays relatively more optimistic behavior. The opposite holds for the (-, -) pattern. A (+, -) pattern of the signs of coefficients indicates that small probabilities are overweighted and large probabilities are underweighted more strongly, when the value of the explanatory variable increases. This $(+,-)$ pattern results in a more curved probability weighting function, i.e. the curve deviates more strongly from linear probability weighting. We label this type of behavior as "less rational". A $(-,+)$ pattern, on the other hand, signals decreasing deviations from linear weighting and may, therefore, be termed "more rational".

In the following, we present general directional hypotheses with respect to two types of questions. The first set of hypotheses is of a more exploratory nature regarding the risk-asfeelings framework; the second set refers to the validity of the decision model.

The risk-as-feelings approach (Loewenstein et al. 2001, Loewenstein and Lerner 2003) supplies the framework for the exploratory hypotheses. Loewenstein and Lerner argue that emotions experienced at the moment of decision making may play a crucial role in behavior. The authors distinguish between anticipatory and incidental influences of immediate emotions. Anticipatory feelings stem from thinking about the future consequences of the decision at hand. One critical determinant of anticipatory emotion is perceived control over the environment, even if such control does not affect probabilities and outcomes. Loewenstein and Lerner 2003 cite evidence in favor of the view that people who believe they are in control of their environment tend to show less intense emotional reactions. Incidental affect, on the other hand, is unrelated to the decision at hand, but may still have a significant impact on judgment and choice. In order to investigate the effects of immediate emotions on probability weighting, we therefore focus on two potential factors: locus of control and state of mood.

Investment choices in an economic experiment are not characterized by varying degrees of controllability. Therefore, we cannot test directly for any effects of perceived control, but must rather concentrate on a person's general disposition towards feelings of control as measured by the internal/external locus of control scale. Internal people perceive themselves 
as having control over their environments and may, therefore, be less strongly subject to anticipatory emotions than are external people. A number of studies, described in Loewenstein and Lerner (2003), indicate that anticipatory affective responses seem to be relatively insensitive to probabilities ${ }^{6}$. If people with an internal locus of control are less vulnerable to anticipatory feelings, they should also be less prone to discounting probability information. We therefore hypothesize that internal people are subject to weaker probability distortions than are external people.

HYPOTHESIS 1 (LOCUS OF CONTROL): A higher degree of self reported LOCONTROL is associated with more rational probability weighting, i.e. with a (-, +) pattern for the signs of the coefficients.

We now turn to states of mood, which are the incidental factors influencing immediate emotions. Numerous studies have shown that people in good moods make optimistic judgments and choices, while those in bad moods make pessimistic judgments and choices (see the references in Loewenstein and Lerner 2003). Wright and Bower (1992), for example, report a large and consistent positive relationship between mood and subjective probabilities. Subjects in their study - while the experimenters induced mood states - were confronted with hypothetical events in a variety of contexts, and had to assess how likely a future occurrence of these events was. In the course of the experiment, happy people turned out to be more optimistic, they assigned higher probabilities to positive events and lower probabilities to negative events than did those in a neutral or bad mood state. The second interesting result was the detection of a susceptibility effect: Subjects judging more frequently occurring events exhibited higher susceptibility to mood effects than when judging less frequently occurring events. If we assume that these findings carry over to a situation when given probabilities are weighted, rather than unknown probabilities assessed, the following hypothesis results.

HYPOTHESIS 2 (MOOD CONGRUENCE): Better mood is associated with higher probability weights, i.e. with a (+, +) pattern of coefficients. Moreover, the coefficients of the mood variable rise with the level of probability.

Isen and her colleagues contest the validity of mood-congruent behavior in the context of risk taking, however. They argue that a more optimistic probability judgment does not necessarily lead to a higher willingness to accept a given lottery. As Isen and Patrick (1983) show, happy decision makers are much less willing to gamble than control subjects, even though they are

\footnotetext{
${ }^{6}$ In a similar vein, Rottenstreich and Hsee (2001) show that affect-laden outcomes are associated with a more
} 
generally more optimistic about their probability of winning. Isen and Labroo (2003) argue that positive affect only leads to increased risk-taking when the risk is hypothetical or small. In contrast, positive affect leads to reduced risk-taking in comparison with control subjects in situations where the risk is real or sizable. This phenomenon can be explained by mood maintenance theory, which postulates that people in a good mood stand to lose their affective state as well as their stake, and therefore behave more cautiously. The study by Kliger and Levy (2003), using weather conditions as a proxy for state of mood, indeed finds that good mood is associated with investors being less willing to tolerate risk in real capital market decisions, while bad mood is associated with higher risk tolerance. Mood could act on the valuation of a prospect's outcomes and/or on the probability weights. In the latter case, good mood should depress $w(p)$.

HYPOTHESIS 3 (MOOD MAINTENANCE): People who report being in a good mood tend to be relatively more pessimistic than people in a neutral or bad mood, i.e. a (-, -) pattern for the signs of the regression coefficients will emerge.

The mood maintenance hypothesis clearly conflicts with the mood congruence hypothesis, unless mood maintenance influences the valuation of outcomes rather than probability weighting. In this case, strong undervaluation of outcomes could override more optimistic probability judgment and induce happier people to make overall relatively more risk averse choices. But as we already mentioned above, our estimates of value functions do not support this view. There is no significant relationship between the mood variables and the curvature parameter of the valuation function.

However, there is another aspect we would like to discuss. The majority of studies induced mood states and, therefore, measured the impact of a situational, possibly very short-lived, mood state. We introduced the variable PERMOOD in order to explore any potential effects of a more persistent kind of mood state. It is not clear a priori what kind of effect we should expect. For example, one could speculate that people in a persistently good mood are more robust and therefore tend to take greater risks. But of course, the mood maintenance hypothesis might also hold.

The following hypotheses present a kind of litmus test for our decision model. They relate to CHEERFULNESS and EXVALUE. As far as CHEERFULNESS is concerned, we 
hypothesize more cheerful people to be more optimistic about gains than less cheerful people are. By definition, the variable includes the attributes optimism and non-pessimism, and we would expect people with high scores on CHEERFULNESS to behave accordingly, i.e. to judge probabilities more favorably. Therefore, we conjecture the following relationship between the signs of estimated coefficients and cheerfulness to hold.

HYPOTHESIS 4 (CHEERFULNESS): People reporting a higher degree of cheerfulness weight probabilities more highly. Thus, a (+, +) pattern of regression coefficients will emerge.

The last hypothesis concerns the decision criterion the subjects use. Obviously, people who apply the expected value as one decision criterion when judging prospects should stick more closely to linear weighting. We therefore hypothesize the following:

HYPOTHESIS 5 (EXPECTED VALUE CRITERION): People who use a prospect's expected payoff as a decision criterion exhibit more rational behavior than those who do not, i.e. a (-, +) pattern of signs of coefficients will arise.

\section{Results}

The parameter estimates of the regression model (3) are summarized in Table 5. The values of $\mathrm{R}$-squared are in the range of 0.30 to 0.56 , reflecting the variables' higher explanatory power in the upper range of probabilities. The constant is large and significantly negative for high probabilities, implying that subjects exhibit a substantial degree of risk aversion which our explanatory variables cannot account for. As expected, the dummy variable FEMALE turns out to be highly significant for larger probabilities, corroborating the findings by Fehr-Duda et al. on the gender-specific probability weighting functions.

\section{(insert Table 5)}

Since we could not estimate direct interaction effects with gender in model (3) due to multicollinearity, we estimated the regression model for each of the sexes separately. As Tables 6 and 7 show, the explanatory variables capture a large fraction of the variation in the 
probability weights, particularly for women. The R-squared values for the male model amount to more than 0.5 , those for the female model are in the range between 0.71 and 0.82 . These values imply that the gender-specific models perform much better than the pooled regression. In the following, we will discuss our findings concerning the hypotheses above, using the gender-specific results.

For convenience, we display the results for each variable in a separate box, incorporating the corresponding lines of Tables 6 and 7. We show the estimated coefficients for each level of probability for both sexes. Coefficients marked with * $(* *, * * *)$ are significant at the $10 \%$ $(5 \%, 1 \%)$ level. Figures 1 to 7 display the changes in mean probability weights ${ }^{7}$ associated with an increase in a specific variable's value by one standard deviation. As far as the expected value criterion is concerned, mean probability weights are constructed by setting EXVALUE $=0$, with all the other variables set at their mean values. The effect of the criterion on probability weights is measured in terms of change in the mean weights resulting from EXVALUE $=1$.

(insert Tables 6, 7)

We first discuss the results concerning determinants of immediate emotions. Perceived control over one's environment may make people less susceptible to anticipatory feelings and, consequently less prone to probability distortions.

RESULT 1 (LOCUS OF CONTROL): A higher degree of internal locus of control is associated with more pessimistic choices by women and more rational choices by men.

Support. The curves in Figures 1 and 2 show a surprising gender-specific pattern. Internal men deviate significantly less from linear weighting than do external men (Figure 2), whereas internal women exhibit more depressed probability weights than external women (Figure 1). The male coefficients displayed in Box 1 below turn from significantly negative to significantly positive. Women react in a very different way to the locus of control variable. Women with a strong perception of having control over their lives exhibit highly significantly more pessimism than women with an external locus of control, with the effect fading out for high probabilities. Thus, Hypothesis 1 can clearly be confirmed for men, but not for women.

\footnotetext{
${ }^{7}$ Mean probability weights can be inferred from Table 1.
} 
Box 1: Regression Coefficients of LOCONTROL

\begin{tabular}{|lllllllll|}
\hline LOCONTROL & Probability & $5 \%$ & $10 \%$ & $25 \%$ & $50 \%$ & $75 \%$ & $90 \%$ & $95 \%$ \\
\hline Women & Coefficient & $-0.089^{* \star *}$ & $-0.106^{* * *}$ & $-0.112^{* \star *}$ & $-0.118^{* * *}$ & $-0.084^{* *}$ & -0.038 & -0.013 \\
Men & Coefficient & $-0.049^{* *}$ & $-0.040^{*}$ & -0.009 & 0.036 & $0.073^{* \star *}$ & $0.083^{* *}$ & 0.079 *** \\
\hline
\end{tabular}

(insert Figures 1, 2)

The other potential factor influencing immediate emotions is state of mood. We presented conflicting hypotheses on mood: mood congruence and mood maintenance.

RESULT 2 (MOOD CONGRUENCE): Women in a better immediate mood weight probabilities more highly than do women in a worse than average mood. Men's probability weighting is not sensitive to immediate mood.

Support. Women who reported a better than average state of mood on the day of the experiment judge probabilities more optimistically; as Figure 3 shows, probability weights rise substantially in this case. The female regression coefficients are significant for the whole range of probabilities. There is also evidence for the susceptibility effect. The effect of immediate mood on probability weights rises with increasing probability. Therefore, the mood congruence hypothesis can be confirmed for women's immediate mood. The estimates for the male model show no significant effect whatsoever.

Box 2: Regression Coefficients of IMMOOD

\begin{tabular}{|lllllllll|}
\hline IMMOOD & Probability & \multicolumn{1}{c}{$5 \%$} & \multicolumn{1}{c}{$10 \%$} & $25 \%$ & $50 \%$ & $75 \%$ & $90 \%$ & $95 \%$ \\
\hline Women & Coefficient & $0.029^{* \star}$ & $0.040^{* \star \star}$ & $0.058^{* \star *}$ & $0.074^{* \star *}$ & $0.086^{* \star \star}$ & $0.091^{* *}$ & $0.092^{* \star \star}$ \\
Men & Coefficient & -0.001 & 0.000 & 0.001 & 0.001 & 0.001 & 0.001 & 0.002 \\
\hline
\end{tabular}

(insert Figure 3)

Immediate mood affects women's probability weights strongly and significantly. Women in a better immediate mood tend to be relatively less risk averse than those reporting an average mood. The mood maintenance hypothesis can be rejected for immediate mood, but not for persistent mood, as the next result shows.

RESULT 3 (MOOD MAINTENANCE): Women who were in a relatively better mood in the month prior to the experiment are comparatively more pessimistic. So are men, but the effect is not significant. 
Support. As Figure 4 indicates, the effect of a persistently better state of mood on women is significantly negative, with stable magnitudes over the whole range of probabilities. The coefficients in Box 3 below show the effect to be highly significant. The mood maintenance hypothesis holds for women's long-term state of mood. The male coefficients display the expected sign, but are insignificant over the range of probabilities.

Box 3: Regression Coefficients of PERMOOD

\begin{tabular}{|lllllllll|}
\hline PERMOOD & Probability & $5 \%$ & $10 \%$ & $25 \%$ & $50 \%$ & $75 \%$ & $90 \%$ & $95 \%$ \\
\hline Women & Coefficient & $-0.093^{* \star}$ & $-0.099^{\star \star \star}$ & $-0.105^{\star \star \star}$ & $-0.104^{\star \star \star}$ & $-0.098^{* \star}$ & $-0.096^{* \star}$ & $-0.097^{* \star}$ \\
Men & Coefficient & -0.025 & -0.027 & -0.030 & -0.034 & -0.035 & -0.028 & -0.021 \\
\hline
\end{tabular}

(insert Figure 4)

The next two results relate to the plausibility of the decision model. People who characterize themselves as optimistic should behave optimistically, and those who take expected payoffs into account should be less prone to probability distortions.

RESULT 4 (CHEERFULNESS): More cheerful subjects assess probabilities more highly.

Support. The mean curves for women (Figure 5) and for men (Figure 6) show larger probability weights when cheerfulness increases by one standard deviation. As the genderspecific coefficients in Box 4 indicate, the effects are highly significant for women over the whole range of probabilities with stable magnitudes in the range of $25 \%$ to $95 \%$. The pattern looks somewhat different for men. Coefficients are stable and large in the lower range and then become insignificant for higher probabilities, which results in a more elevated but also more S-shaped curve (see Figure 3). Hypothesis 4 can be confirmed for both sexes, but the effect is clearly stronger for women.

\section{Box 4: Regression Coefficients of CHEERFULNESS}

\begin{tabular}{|llccccccc|}
\hline CHEERFULNESS & Probability & $5 \%$ & $10 \%$ & $25 \%$ & $50 \%$ & $75 \%$ & $90 \%$ & $95 \%$ \\
\hline Women & Coefficient & $0.086^{* * *}$ & $0.108^{* * *}$ & $0.134^{* * *}$ & $0.146^{* * *}$ & $0.142^{* * *}$ & $0.136^{* *}$ & $0.1366^{\text {***}}$ \\
Men & Coefficient & $0.113^{* * *}$ & $0.121^{* * *}$ & $0.119^{* * *}$ & $0.094^{* * *}$ & 0.052 & 0.010 & -0.012 \\
\hline
\end{tabular}

(insert Figures 5,6)

RESULT 5 (EXPECTED VALUE CRITERION): Subjects who use expected payoffs as a decision criterion deviate less strongly from linear weighting than subjects who do not do so. Considering expected values of payoffs is a male phenomenon. 
Support. Only 3 females in our sample report using the expected value as a decision criterion. This is quite surprising, since $59 \%$ of the female students major in technical or natural sciences requiring sound mathematics training. The male probability weights, however, display the hypothesized pattern of more rational probability weighting (see Figure 7). The regression coefficients turn from significantly negative to significantly positive.

Box 5: Regression Coefficients of EXVALUE

\begin{tabular}{|lcccccccc|}
\hline EXVALUE & Probability & $5 \%$ & $10 \%$ & $25 \%$ & $50 \%$ & $75 \%$ & $90 \%$ & $95 \%$ \\
Men & Coefficient & $-0.0622^{* * *}$ & $-0.0622^{* *}$ & $-0.045^{*}$ & -0.005 & 0.035 & $0.054^{* *}$ & $0.055^{* *}$ \\
\hline
\end{tabular}

(insert Figure 7)

\section{Discussion}

We gained three insights from our analysis. First, and most importantly, we were able to pin down some of the determinants of the probability weighting function. And if the R-squared values are anything to go by, we were quite successful at explaining the variation in the probability weights. In our view, the most interesting result concerns the effects of immediate emotions on risk taking. We have shown that incidental factors play an important role in decision making. Probability weights depend on the state of mood and a variance in the state of immediate mood from the normal state of mood seems to matter. The effects of mood state on probability weighting are only significant for women, however. Interestingly, men and women do not report differing scores for state of mood. They do not differ in their selfassessed mood, but rather in the way mood affects their probability judgment. Familiarity (or lack of it) with investment decisions could be a reason for this gender difference. Loewenstein and Lerner (2003) argue that immediate affect does not necessarily influence all types of decisions. In particular, feelings have been shown to influence evaluations of unfamiliar products, while not affecting familiar ones. People with specific factual knowledge about familiar products seem to be less vulnerable to affective influences. Subjects in our experiment had to make decisions on investment opportunities. Since only four women report familiarity with investment decisions, the gender difference in susceptibility to mood states could be due to differing familiarity with these decisions.

Aside from states of mood, we also explored the role of locus of control in probability weighting. Higher perceived control should theoretically mitigate the intensity of anticipatory 
feelings and, consequently, reduce their effect on the curvature of the probability weighting function. However, since the controllability of the environment was constant, we did not tie the alleged link between the intensity of anticipatory feelings and perceived control to features of the decision situation, but rather to the subjects' personality. We hypothesized that people who generally feel in control of their lives will be less susceptible to anticipatory feelings. Men's behavior confirms the hypothesis of stronger rationality of internal persons. We can only speculate why internal women's choices correspond to more pessimistic probability weighting than external women's. More cautious women might not experience negative consequences often and therefore believe that they have control over their environment. In any case, the relationship between probability perception and locus of control needs to be more deeply explored.

Second, we addressed a methodological issue concerning the reliability of the estimation procedure. We recorded people's choices, inferred certainty equivalents from these choices, estimated parameters of the probability weighting function, and finally regressed the estimated probability weights on a set of explanatory variables. In the end, the regression results indeed exhibited the patterns we most expected. More cheerful people assess probabilities more highly in the context of investment choices, and people using expected values as a decision criterion tend to deviate less strongly from linear weighting. Moreover, the factors studied only affect probability weighting and not the valuation of outcomes. These findings confirm that the estimation procedure can correctly reflect the effects of the different components of the decision model. We consider this result to be quite reassuring.

Third, the gender-specific models outperform the pooled regression model, as the relationships between dependent and explanatory variables are highly gender-specific. Even though the model explains female probability weights extraordinarily well, we still find a substantial negative and significant constant. Therefore, the factors responsible for women's higher risk aversion in investment decisions still need to be unearthed. This issue is particularly interesting, as not only the majority of laboratory experiments but also the field surveys conducted so far have consistently identified women to be the more risk averse sex (Eckel and Grossman in press).

We suggest two routes for future research to shed more light on the determinants of individual probability weights. One route concerns another empirical test of the relationship between 
incidental affect and probability weights. In our study, we base the states of mood variables on self-reports. Ideally, the experimenter should have control over mood states by inducing moods of differing valence before subjects are presented with the decision situations. The other route is related to the relationship between immediate emotions and familiarity of decision domain. The survey by Gneezy and Croson (2004) indicates that professional female managers are less risk averse than women in general. The study by Gysler et al. (2002) shows that gender-specific risk-taking behavior is associated with confidence and financial market knowledge. With increasing objectively measured knowledge, women tend to become relatively more risk seeking whereas men become less risk prone. Women seem to be very cautious when confronted with decisions in an unfamiliar domain. Whether this behavior is due to stronger anticipatory feelings still needs to be explored.

Returning to the questions posed in the introduction, we offer the following answers. Specific personality traits, mood states, and the decision guideline used can explain some of the heterogeneity of probability weighting. The effects are highly gender-specific, and there is still a substantial unexplained residuum in gender-specific risk aversion. In our opinion, emotions and familiarity with decision domain are promising candidates for better understanding the risk-taking behaviors of women and men.

\section{References}

Abdellaoui, Mohammed (2000). Parameter-Free Elicitation of Utilities and Probability Weighting Functions. Management Science 46:1497-1512

Camerer, Colin F. (1992). Recent Tests of Generalizations of Expected Utility Theory, in: Edwards, W. (ed.), Utility: Theories, Measurement, and Applications, Boston, MA, Kluwer Academic Publishers.

Croson, Rachel and Gneezy, Uri (2004). Gender Differences in Preferences, mimeo.

Eckel, Catherine C. and Grossman, Philip J. (in press). Differences in the Economic Decisions of Men and Women: Experimental Evidence. In: Plott, Charles and Smith, Vernon (eds.). Handbook of Experimental Results, New York, Elsevier. 
Etchart-Vincent, Nathalie (2004). Is Probability Weighting Sensitive to the Magnitude of Consequences? An Experimental Investigation on Losses. Journal of Risk and Uncertainty 28:217-235.

Fehr-Duda, Helga, De Gennaro, Manuele, and Schubert, Renate (in press). Gender, Financial Risk, and Probability Weights. Theory and Decision, Special Issue

Fischbacher, Urs (1999), Z-Tree. Zurich Toolbox for Readymade Economic Experiments.

Working Paper No. 21, Institute of Empirical Economic Research, University of Zurich.

Gonzalez, Richard and Wu, George (1999). On the Shape of the Probability Weighting Function. Cognitive Psychology 38:129-166.

Gysler, Matthias, Brown Kruse, Jamie, and Schubert, Renate (2002). Ambiguity and Gender Differences in Financial Decision Making: An Experimental Examination of Competence and Confidence Effects. Center for Economic Research, Swiss Federal Institute of Technology, Working Paper.

Isen, Alice M. and Labroo, Aparna A. (2003). Some Ways in Which Positive Affect Facilitates Decision Making and Judgment. In: Schneider, Sandra L. and Shanteau, James (eds.). Emerging Perspectives on Judgment and Decision Research. Cambridge University Press.

Isen, Alice M. and Patrick, R. (1983). The Effect of Positive Feeling on Risk-Taking: When the Chips Are Down. Organizational Behavior and Human Performance 31: 194-202.

Kahneman, Daniel and Tversky, Amos (1979). Prospect Theory: An Analysis of Decision under Risk. Econometrica 47:263-291.

Kliger, Doron and Levy, Ori (2003). Mood-Induced Variation in Risk Preferences. Journal of Economic Behavior and Organization 52: 573-584.

Lattimore, Pamela K., Baker, Joanna K., and Witte, Ann D. (1992). The Influence of Probability on Risky Choice: A Parametric Examination. Journal of Economic Behavior and Organization 17:377-400.

Loewenstein, George and Lerner, Jennifer S. (2003). The Role of Affect in Decision Making. In: Davidson, Richard J., Scherer, Klaus R. and Goldsmith, H. Hill. Handbook of Affective Sciences. Oxford University Press.

Lowenstein, George, Weber, Elke U., Hsee, Christopher K. and Welch, Ned (2001). Risk as Feelings. Psychological Bulletin 127/2:267-286. 
Rottenstreich, Yuval and Hsee, Christopher K. (2001). Money, Kisses and Electric Shocks: On the Affective Psychology of Risk. Psychological Science 12:185-190. Starmer, Chris (2000). Developments in Non-Expected Utility Theory: the Hunt for a Descriptive Theory of Choice under Risk. Journal of Economic Literature 38:332382 .

Tversky, Amos and Fox, Craig R. (1995). Weighing Risk and Uncertainty. Psychological Review 102:269-283.

Tversky, Amos and Kahneman, Daniel (1992). Advances in Prospect Theory: Cumulative Representation of Uncertainty. Journal of Risk and Uncertainty 5:297-323.

Walther, Herbert (2003). Normal-Randomness Expected Utility, Time Preference, and Emotional Distortions. Journal of Economic Behavior and Organization 52:253266.

Wright, William F. and Bower, Gordon H. (1992). Mood Effects on Subjective Probability Assessment. Organizational Behavior and Human Decision Processes $52: 276-291$.

$\mathrm{Wu}$, George and Gonzalez, Richard (1996). Curvature of the Probability Weighting Function. Management Science 42:1676-1690

$\mathrm{Wu}$, George and Gonzalez, Richard (1999). Nonlinear Probability weights in Choice under Uncertainty. Management Science 45:74-85

$\mathrm{Wu}$, George and Markle, Alex B. (2004). An Experimental Test of Gain-Loss Separability in Prospect Theory. Graduate School of Economics, University of Chicago, Working Paper.

$\mathrm{Wu}$, George, Zhang, Jiao, and Gonzalez, Richard (in press). Decision under Risk. In: Harvey, Nigel and Koehler, Derek (eds.). Blackwell Handbook of Judgment and Decision Making. 


\section{APPENDIX}

\section{Questions administered at the end of the Fehr-Duda et al. experiment}


1. How do you assess your character? Which attributes apply to you? (Please tick each attribute once only)

\begin{tabular}{|c|c|c|c|c|c|}
\hline & true & $\begin{array}{l}\text { rather } \\
\text { true }\end{array}$ & $\begin{array}{l}\text { rather not } \\
\text { true }\end{array}$ & not true & don't know \\
\hline \multicolumn{6}{|l|}{ cheerful } \\
\hline \multicolumn{6}{|c|}{ „lucky bugger“ } \\
\hline \multicolumn{6}{|c|}{ content } \\
\hline \multicolumn{6}{|c|}{ pessimistic } \\
\hline \multicolumn{6}{|c|}{ optimistic } \\
\hline anxious & & & & & \\
\hline
\end{tabular}

Please mark the number applying to your situation:

2. Are you able to achieve your aims and to carry out your plans?

$\begin{array}{ccccccc}\text { absolutely } & & & \text { neutral } & & \text { not at all } \\ 0 & 1 & 2 & & 3 & 4 & 5\end{array}$

3. How often do you have the feeling that fate determines what happens to you?

$\begin{array}{cccccc}\text { never } & \text { seldom } & \text { not very often } & \text { rather often } & \text { often } & \text { permanently } \\ 0 & 1 & 2 & 3 & 4 & 5\end{array}$

4. How have you generally felt during the past month?

$\begin{array}{cccccc}\text { splendid } & \text { very well } & \text { well } & \text { to and fro } & \text { rather bad } & \text { very bad } \\ 0 & 1 & 2 & 3 & 4 & 5\end{array}$

5. How often have you felt as fresh as paint when waking up in the morning during the past month?

$\begin{array}{cccccc}\text { never } & \text { seldom } & \text { not very often } & \text { rather often } & \text { almost every day } & \text { every day } \\ 0 & 1 & 2 & 3 & 4 & 5\end{array}$

6. How satisfying has your life been during the past month?
absolutely
neutral
$\begin{array}{llll}0 & 1 & 2 & 3\end{array}$
4
not at all
5

7. How often have you felt tired, burned-out and exhausted during the past month?

$\begin{array}{cccccc}\text { never } & \text { seldom } & \text { not very often } & \text { rather often } & \text { almost every day } & \text { every day } \\ 0 & 1 & 2 & 3 & 4 & 5\end{array}$

8. How often have you felt under pressure or stressed during the past month?

$\begin{array}{cccccc}\text { never } & \text { seldom } & \text { not very often } & \text { rather often } & \text { almost every day } & \text { every day } \\ 0 & 1 & 2 & 3 & 4 & 5\end{array}$


9. How do you feel today?

bad

0

1

as usual 3

4

very good

2

5

10. Please explain briefly the criteria influencing your decisions during the experiment: 
Table 1: Mean Estimated Value Function Parameters and Mean Estimated Deviations of Probability Weights from Probabilites

\begin{tabular}{|c|c|c|c|c|c|c|c|c|}
\hline \multirow[b]{4}{*}{ Women and Men } & \multirow{4}{*}{$\begin{array}{c}\text { Value Function } \\
\text { Curvature } \\
1.059\end{array}$} & \multicolumn{7}{|c|}{ Probability } \\
\hline & & 0.05 & 0.1 & 0.25 & 0.5 & 0.75 & 0.9 & 0.95 \\
\hline & & \multicolumn{7}{|c|}{ Mean Deviations } \\
\hline & & 0.122 & 0.123 & 0.072 & -0.054 & -0.174 & -0.210 & -0.198 \\
\hline Women & 1.123 & 0.137 & 0.130 & 0.060 & -0.094 & -0.239 & -0.290 & -0.282 \\
\hline Men & 1.013 & 0.111 & 0.117 & 0.080 & -0.025 & -0.127 & -0.152 & -0.137 \\
\hline
\end{tabular}


Table 2: Summary Statistics for the Explanatory Variables

\begin{tabular}{|lcrrrrrr|}
\hline \multicolumn{2}{l}{ Women and Men (69 Observations) } & & & & \\
\multicolumn{1}{|c}{ Variable } & Question \# & Median & Mean & Std.Dev. & Min & Max & Sum \\
\hline CHEERFULNESS & 1 & 2.2 & 2.09 & 0.56 & 1.0 & 3.0 \\
LOCONTROL & 2,3 & 3.5 & 3.54 & 0.67 & 2.0 & 5.0 \\
IMMOOD & 9 & 3 & 3.01 & 1.25 & 0.0 & 5.0 \\
PERMOOD & $4-8$ & 3 & 3.02 & 0.71 & 0.8 & 5.0 \\
EXVALUE & 10 & 0 & 0.33 & 0.47 & & & 23 \\
FEMALE & Gender Dummy & 0 & 0.42 & 0.50 & & & 29 \\
\hline
\end{tabular}

\begin{tabular}{|lrrrrr|}
\hline Women (29 Observations) & & & & & \\
$\quad$ & Median & Mean & Std.Dev. & Min & Max Sum \\
\hline Variable & 2.2 & 2.21 & 0.46 & 1.6 & 3.0 \\
LHEERFULNESS & 3.5 & 3.57 & 0.55 & 2.5 & 5.0 \\
IMMONTROL & & & & & \\
PERMOD & 3 & 3.03 & 1.40 & 0.0 & 5.0 \\
EXVALUE & 3 & 2.96 & 0.74 & 0.8 & 4.4 \\
\hline
\end{tabular}

\begin{tabular}{|lrrrrr|}
\hline $\begin{array}{l}\text { Men (40 Observations) } \\
\quad \text { Median }\end{array}$ & Mean & Std.Dev. & Min & Max Sum \\
\hline Variable & 2.1 & 2.01 & 0.61 & 1.0 & 3.0 \\
CHEERFULNESS & 3.5 & 3.53 & 0.75 & 2.0 & 5.0 \\
LOCONTROL & & & & & \\
& 3 & 3.00 & 1.15 & 0.0 & 5.0 \\
IMMOOD & 3 & 3.07 & 0.69 & 1.6 & 5.0 \\
PERMOOD & 0.5 & 0.50 & 0.51 & & \\
EXVALUE & & & & & \\
\hline
\end{tabular}


Fehr-Duda et al.: Determinants of Probability Weights

Table 3: Significant Partial Correlations of Probability Weights with Explanatory Variables

* $10 \%-,{ }^{* *} 5 \%-,{ }^{* * *} 1 \%$-Significance

\begin{tabular}{|c|c|c|c|c|c|c|c|}
\hline $\begin{array}{c}p \\
\text { Mean } w(p)-p\end{array}$ & $\begin{array}{r}5 \% \\
12 \%\end{array}$ & $\begin{array}{l}10 \% \\
12 \%\end{array}$ & $\begin{array}{r}25 \% \\
7 \%\end{array}$ & $\begin{array}{l}50 \% \\
-5 \%\end{array}$ & $\begin{array}{r}75 \% \\
-17 \%\end{array}$ & $\begin{array}{r}90 \% \\
-21 \%\end{array}$ & $\begin{array}{r}95 \% \\
-20 \%\end{array}$ \\
\hline IMMOOD & & & & & $0.243^{* *}$ & $0.276^{* *}$ & $0.293^{* \star}$ \\
\hline PERMOOD & & & & & 0.236 * & $0.264^{* *}$ & $0.276^{* *}$ \\
\hline CHEERFULNESS & $0.230 *$ & $0.253^{* *}$ & $0.286^{* *}$ & $0.280^{* *}$ & 0.211 * & & \\
\hline EXVALUE & & & & & $0.280 * *$ & $0.310^{* * *}$ & $0.304^{* *}$ \\
\hline FEMALE & & & & $-0.295 * *$ & $-0.420 * * *$ & $-0.470^{* * *}$ & $-0.484^{* * *}$ \\
\hline
\end{tabular}


Table 5: Seemingly Unrelated Regression of $w(p)-p$ on the Questionnaire Variables Women and Men

* $10 \%-,{ }^{* *} 5 \%-,{ }^{* * *} 1 \%$ level of significance

(Standard errors in parentheses)

\begin{tabular}{|c|c|c|c|c|c|c|c|c|}
\hline Explanatory Variables & \# & $5 \%$ & $10 \%$ & $25 \%$ & $50 \%$ & $75 \%$ & $90 \%$ & $95 \%$ \\
\hline \begin{tabular}{|} 
Personality \\
CHEERFULNESS \\
LOCONTROL
\end{tabular} & & $\begin{array}{l}0.089^{* * *} \\
(0.023) \\
-0.058^{* * *} \\
(0.020)\end{array}$ & $\begin{array}{l}0.100^{* * *} \\
(0.026) \\
-0.059^{* * *} \\
(0.023)\end{array}$ & $\begin{array}{l}0.108^{* * *} \\
(0.029) \\
-0.045^{*} \\
(0.025)\end{array}$ & $\begin{array}{l}0.099 * * * \\
(0.031) \\
-0.014 \\
(0.026) \\
\end{array}$ & $\begin{array}{r}0.074 * * \\
(0.032) \\
0.020 \\
(0.028) \\
\end{array}$ & $\begin{array}{r}0.047 \\
(0.033) \\
0.038 \\
(0.028) \\
\end{array}$ & $\begin{array}{r}0.034 \\
(0.033) \\
0.039 \\
(0.028) \\
\end{array}$ \\
\hline \begin{tabular}{|l} 
Mood \\
IMMOOD \\
PERMOOD
\end{tabular} & & $\begin{array}{r}0.004 \\
(0.008) \\
-0.022 \\
(0.018) \\
\end{array}$ & $\begin{array}{r}0.008 \\
(0.009) \\
-0.017 \\
(0.021) \\
\end{array}$ & $\begin{array}{r}0.015 \\
(0.010) \\
-0.006 \\
(0.023) \\
\end{array}$ & $\begin{array}{c}0.021^{* *} \\
(0.010) \\
0.006 \\
(0.024)\end{array}$ & $\begin{array}{c}0.027^{* *} \\
(0.011) \\
0.017 \\
(0.025)\end{array}$ & $\begin{array}{r}0.0311^{* * *} \\
(0.011) \\
0.025 \\
(0.026) \\
\end{array}$ & $\begin{array}{c}0.032 * * * \\
(0.011) \\
0.029 \\
(0.026)\end{array}$ \\
\hline $\begin{array}{c}\text { Expected Value Criterion } \\
\text { EXVALUE }\end{array}$ & 23 & $\begin{array}{l}-0.066^{* * *} \\
(0.023)\end{array}$ & $\begin{array}{l}-0.069^{* * *} \\
(0.025)\end{array}$ & $\begin{array}{l}-0.058^{* *} \\
(0.028)\end{array}$ & $\begin{array}{r}-0.025 \\
(0.030)\end{array}$ & $\begin{array}{r}0.013 \\
(0.031)\end{array}$ & $\begin{array}{r}0.033 \\
(0.032)\end{array}$ & $\begin{array}{r}0.036 \\
(0.032)\end{array}$ \\
\hline $\begin{array}{r}\text { Gender } \\
\text { FEMALE }\end{array}$ & 29 & $\begin{array}{r}-0.011 \\
(0.023)\end{array}$ & $\begin{array}{r}-0.024 \\
(0.026)\end{array}$ & $\begin{array}{l}-0.050 \text { * } \\
(0.029)\end{array}$ & $\begin{array}{l}-0.082 \text { *** } \\
(0.030)\end{array}$ & $\begin{array}{l}-0.1099^{* * *} \\
(0.032)\end{array}$ & $\begin{array}{l}-0.1266^{* * *} \\
(0.033)\end{array}$ & $\begin{array}{l}-0.132 \text { *** } \\
(0.032)\end{array}$ \\
\hline Constant & & $\begin{array}{r}0.243 \\
(0.147)\end{array}$ & $\begin{array}{r}0.197 \\
(0.164)\end{array}$ & $\begin{array}{r}0.000 \\
(0.181)\end{array}$ & $\begin{array}{l}-0.374 \text { ** } \\
(0.192)\end{array}$ & $\begin{array}{l}-0.759^{* * *} \\
(0.202)\end{array}$ & $\begin{array}{l}-0.964^{* * *} \\
(0.207)^{*}\end{array}$ & $\begin{array}{l}-0.998 \text { *** } \\
(0.205)\end{array}$ \\
\hline Controls* & & Yes & Yes & Yes & Yes & Yes & Yes & Yes \\
\hline $\begin{array}{l}\text { Observations } \\
\text { R-squared }\end{array}$ & 69 & $\begin{array}{r}69 \\
0.3501\end{array}$ & $\begin{array}{r}69 \\
0.3183\end{array}$ & $\begin{array}{r}69 \\
0.2954\end{array}$ & $\begin{array}{r}69 \\
0.3604\end{array}$ & $\begin{array}{r}69 \\
0.4699\end{array}$ & $\begin{array}{r}69 \\
0.5394\end{array}$ & $\begin{array}{r}69 \\
0.5637\end{array}$ \\
\hline
\end{tabular}

* Controls: age, disposable income, number of semesters enrolled, major field of study dummies (economics and business administration,

natural and technical sciences), occupation level, economics lecture dummy, familiarity with investment decisions dummy,

familiarity with insurance dummy, familiarity with gambling dummy, personality trait decidedness (average score on resolute, hesitating, indecisive, temporizing,

sponaneous, determined), wellbeing, exhausting experiment, gut decision dummy, total decision time (recorded at the experiment) 
Table 6: Seemingly Unrelated Regression of w(p)-p on the Questionnaire Variables

\section{Women}

* $10 \%-,{ }^{* *} 5 \%-,{ }^{* * *} 1 \%$ level of significance

(Standard errors in parantheses)

\begin{tabular}{|c|c|c|c|c|c|c|c|c|}
\hline Explanatory Variables & $\#$ & $5 \%$ & $10 \%$ & $25 \%$ & $50 \%$ & $75 \%$ & $90 \%$ & $95 \%$ \\
\hline $\begin{array}{l}\text { Personality } \\
\text { CHEERFULNESS } \\
\text { LOCONTROL }\end{array}$ & & $\begin{array}{l}0.086^{* * *} \\
(0.027) \\
-0.089^{* * *} \\
(0.025)\end{array}$ & $\begin{array}{l}0.108^{* * *} \\
(0.031) \\
-0.106^{* * *} \\
(0.030)\end{array}$ & $\begin{array}{l}0.134^{* * *} \\
(0.037) \\
-0.112^{* * *} \\
(0.036)\end{array}$ & $\begin{array}{l}0.1466^{* * *} \\
(0.042) \\
-0.118^{* * *} \\
(0.040)\end{array}$ & $\begin{array}{l}0.142^{* * *} \\
(0.044) \\
-0.084^{* *} \\
(0.043)\end{array}$ & $\begin{array}{l}0.1366^{* * *} \\
(0.046) \\
-0.038 \\
(0.044) \\
\end{array}$ & $\begin{array}{l}0.136 \text { *** } \\
(0.045) \\
-0.013 \\
(0.043) \\
\end{array}$ \\
\hline $\begin{array}{l}\text { Mood } \\
\text { IMMOOD } \\
\text { PERMOOD }\end{array}$ & & $\begin{array}{l}0.029^{* *} \\
(0.012) \\
-0.093^{* * *} \\
(0.026) \\
\end{array}$ & $\begin{array}{l}0.040^{* * *} \\
(0.014) \\
-0.099 * * * \\
(0.030)\end{array}$ & $\begin{array}{l}0.058^{* * *} \\
(0.017) \\
-0.105^{* * *} \\
(0.036) \\
\end{array}$ & $\begin{array}{l}0.074^{* * *} \\
(0.019) \\
-0.104^{* * *} \\
(0.040)\end{array}$ & $\begin{array}{l}0.086^{* * *} \\
(0.021) \\
-0.098^{* *} \\
(0.043) \\
\end{array}$ & $\begin{array}{l}0.091^{* * *} \\
(0.021) \\
-0.096 * * \\
(0.044)\end{array}$ & $\begin{array}{l}0.092^{* * *} \\
(0.021) \\
-0.097^{* *} \\
(0.043)\end{array}$ \\
\hline $\begin{array}{c}\text { Expected Value Criterion } \\
\text { EXVALUE }\end{array}$ & 3 & & & & & & & \\
\hline Constant & & $\begin{array}{r}0.128 \\
(0.171) \\
\end{array}$ & $\begin{array}{c}0.017^{*} \\
(0.200)\end{array}$ & $\begin{array}{r}-0.254 \\
(0.241) \\
\end{array}$ & $\begin{array}{l}-0.672^{* *} \\
(0.270)\end{array}$ & $\begin{array}{l}{ }^{-1.128} 8^{* * *} \\
(0.287)\end{array}$ & $\begin{array}{l}{ }^{-1.467^{* * *}} \\
(0.294)\end{array}$ & $\begin{array}{l}{ }^{-1.602} \\
(0.290)\end{array}$ \\
\hline Controls* & & Yes & Yes & Yes & Yes & Yes & Yes & Yes \\
\hline $\begin{array}{l}\text { Observations } \\
\text { R-squared }\end{array}$ & 29 & $\begin{array}{r}29 \\
0.7534 \\
\end{array}$ & $\begin{array}{r}29 \\
0.7337 \\
\end{array}$ & $\begin{array}{r}29 \\
0.7118 \\
\end{array}$ & $\begin{array}{r}29 \\
0.7120 \\
\end{array}$ & $\begin{array}{r}29 \\
0.7449 \\
\end{array}$ & $\begin{array}{r}29 \\
0.7905 \\
\end{array}$ & $\begin{array}{r}29 \\
0.8176 \\
\end{array}$ \\
\hline
\end{tabular}

* Controls: age, disposable income, number of semesters enrolled, major field of study dummy (natural and technical sciences),

occupation level, economics lecture dummy, familiarity with insurance dummy, personality trait decidedness

(average score on resolute, hesitating, indecisive, temporizing, sponaneous, determined), wellbeing, exhausting experiment, gut decision dummy,

total decision time (recorded at the experiment). 


\section{Table 7: Seemingly Unrelated Regression of w(p)-p on the Questionnaire Variables \\ Men}

* $10 \%-,{ }^{* *} 5 \%-,{ }^{* *} 1 \%$ level of significance

(Standard errors in parentheses)

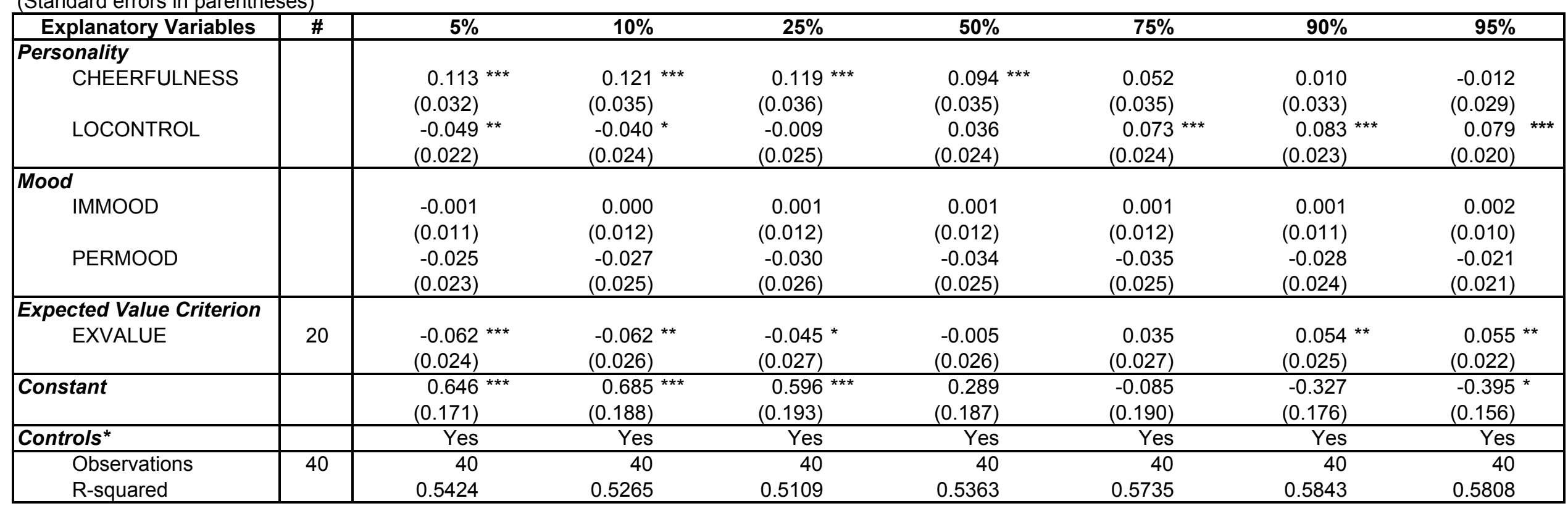

* Controls: age, disposable income, number of semesters enrolled, major field of study dummies (economics and business administration,

natural and technical sciences), occupation level, economics lecture dummy, familiarity with investment decisions dummy,

familiarity with insurance dummy, familiarity with gambling dummy, personality trait decidedness (average score on resolute, hesitating, indecisive, temporizing,

sponaneous, determined), wellbeing, exhausting experiment, total decision time (recorded at the experiment). 
Figure 1: Effect of LOCONTROL on Women's Probability Weights

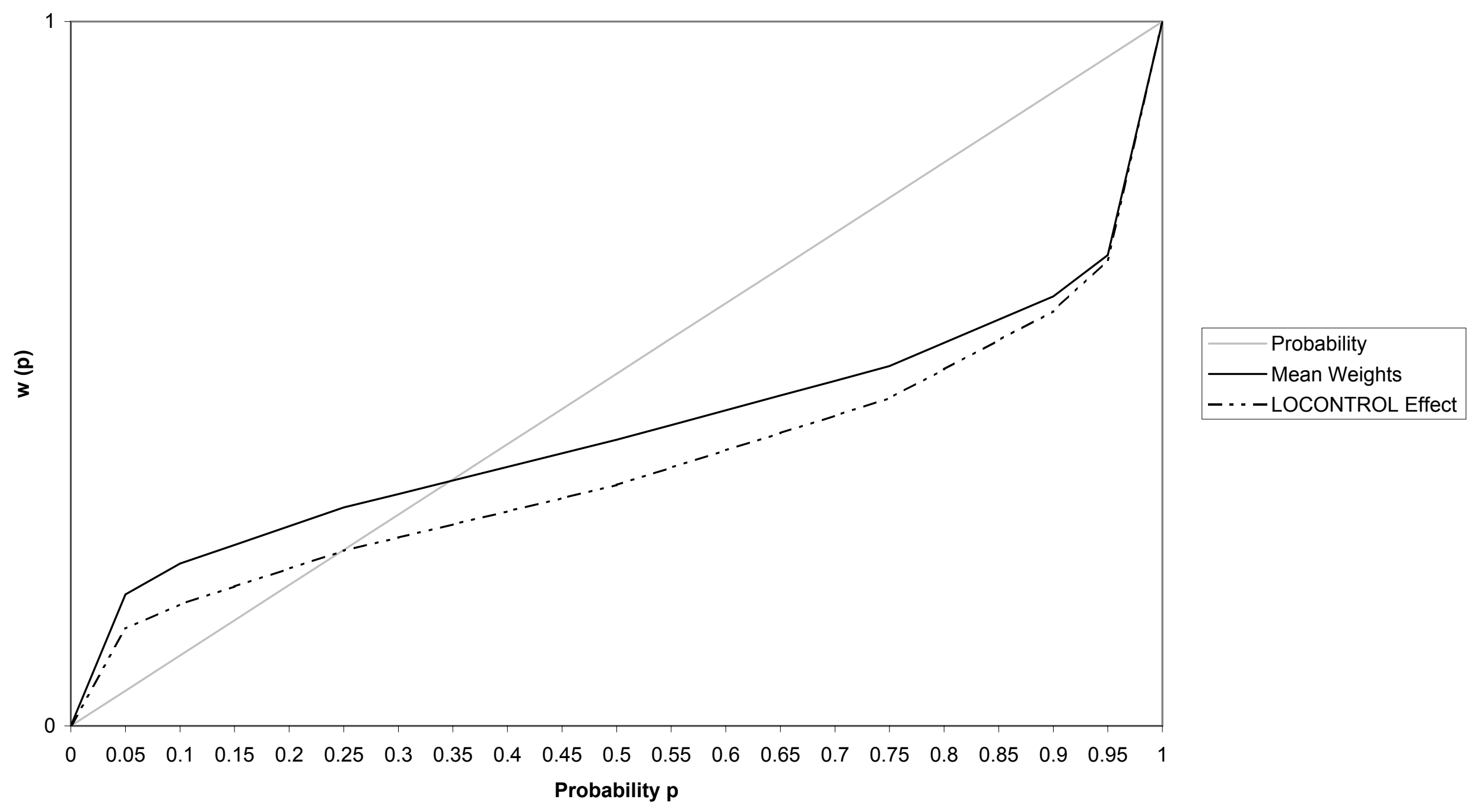


Figure 2: Effect of LOCONTROL on Men's Probability Weights

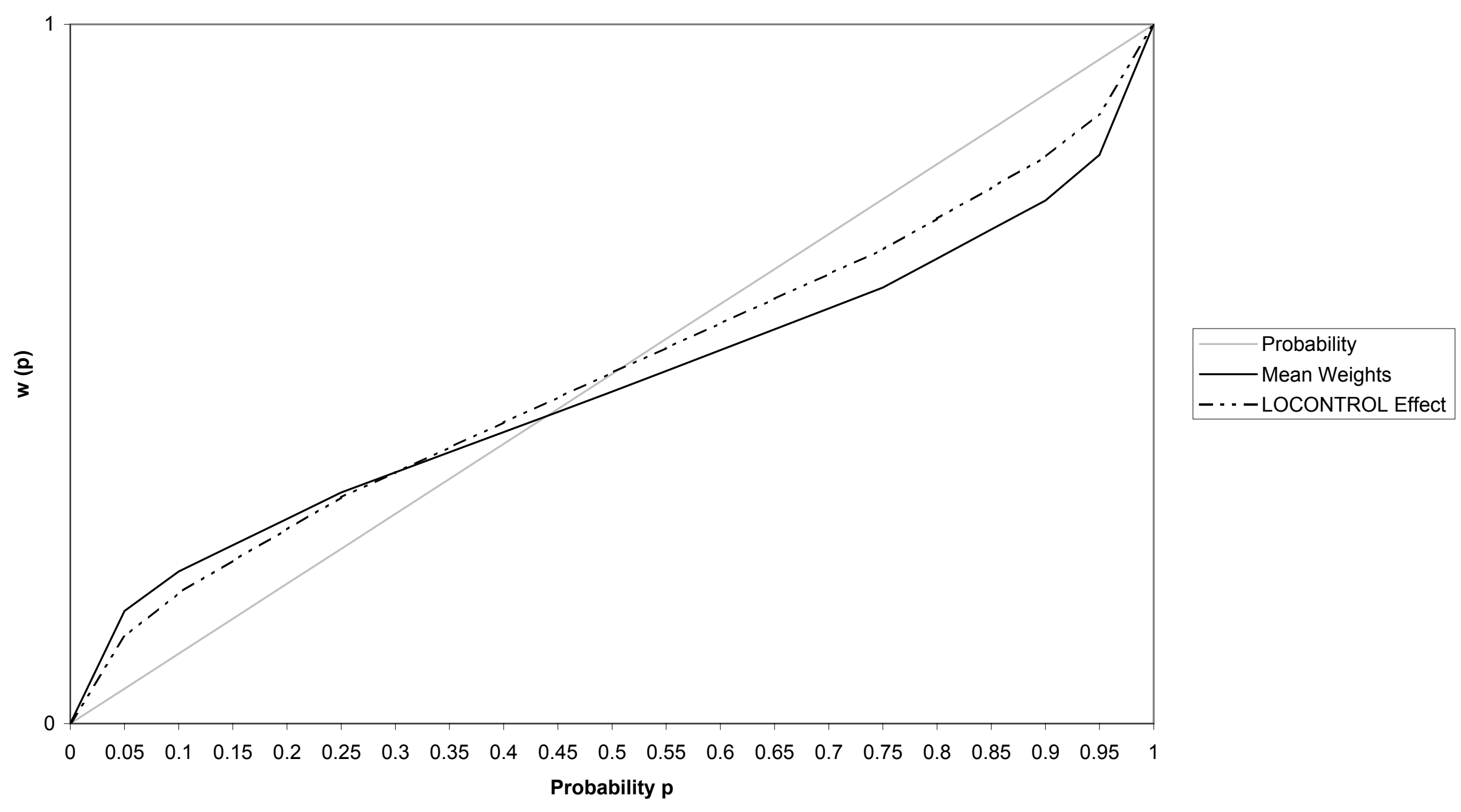


Figure 3: Effect of IMMOOD on Women's Probability Weights

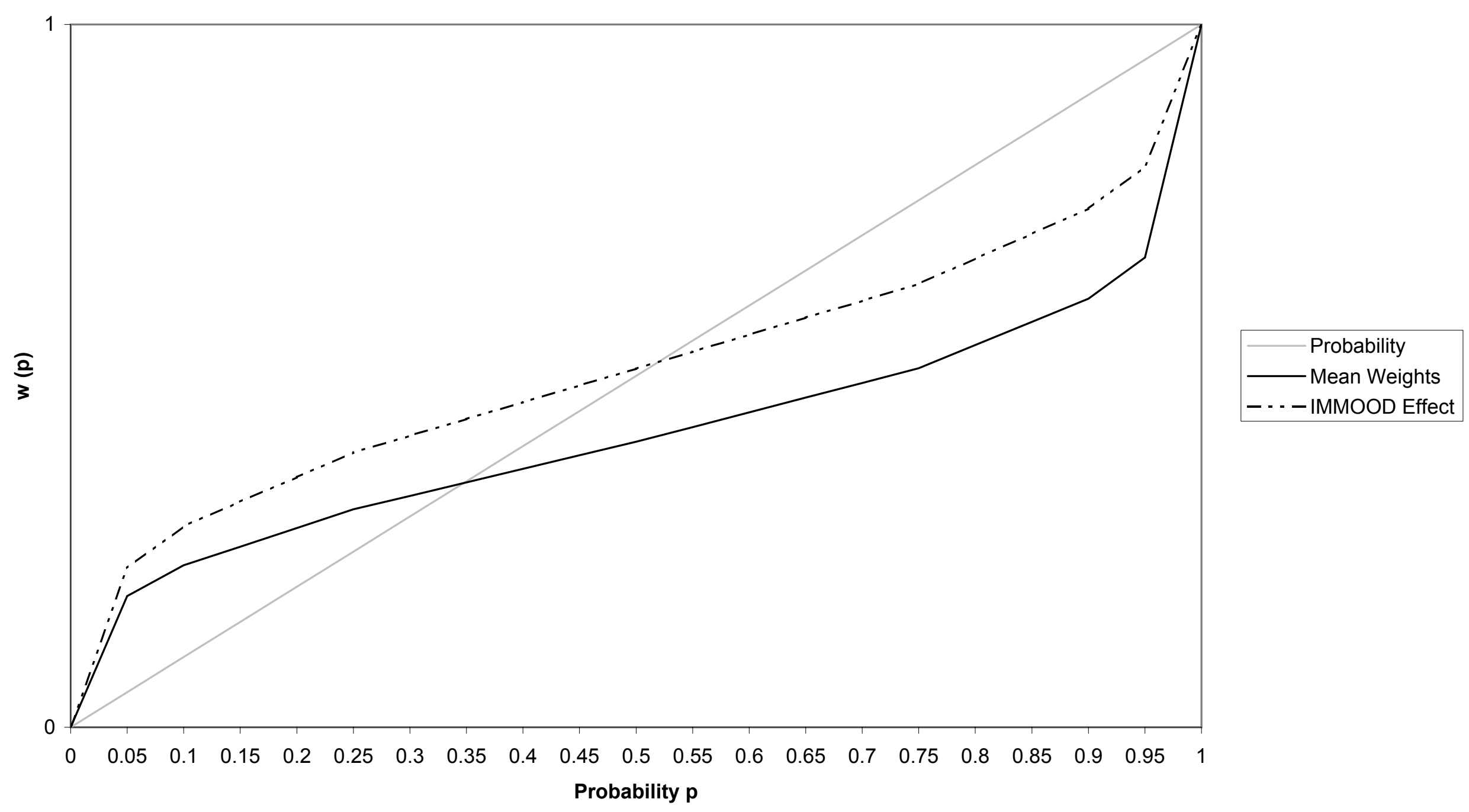




\section{Figure 4: Effect on PERMOOD on Women's Probability Weights}

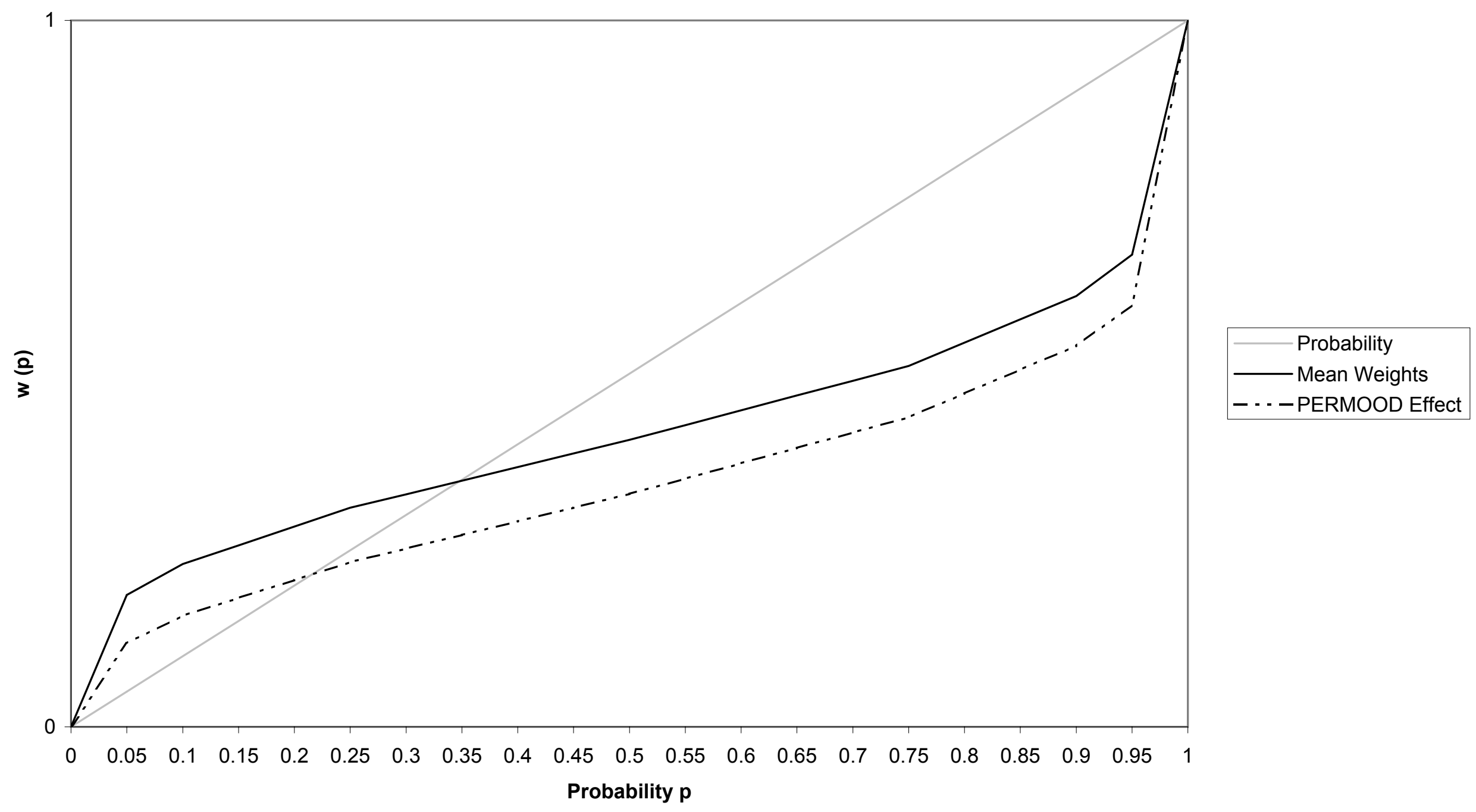




\section{Figure 5: Effect of CHEERFULNESS on Women's Probability Weights}

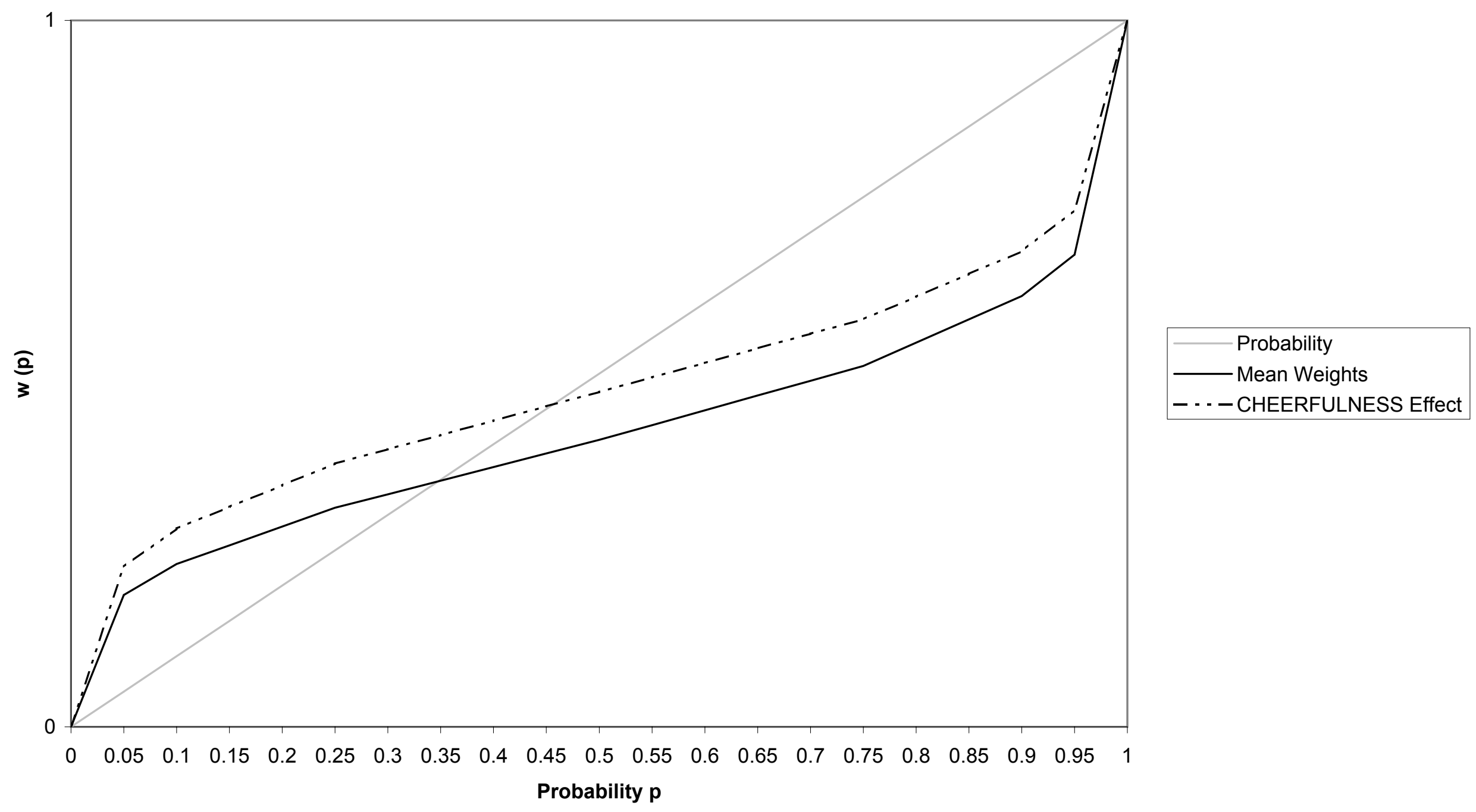


Figure 6: Effect of CHEERFULNESS on Men's Probability Weights

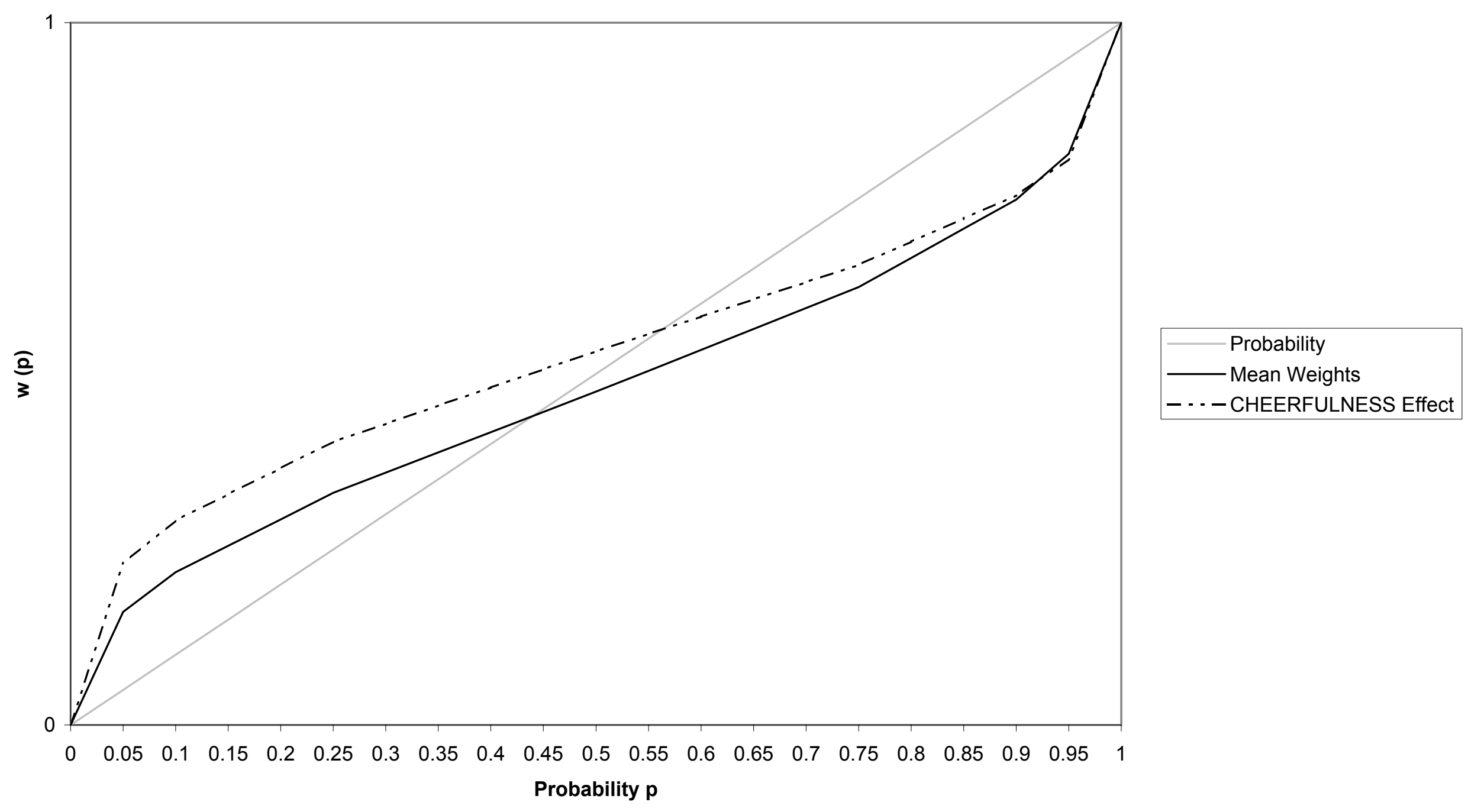




\section{Figure 7: Effect of EXVALUE on Men's Probability Weights}

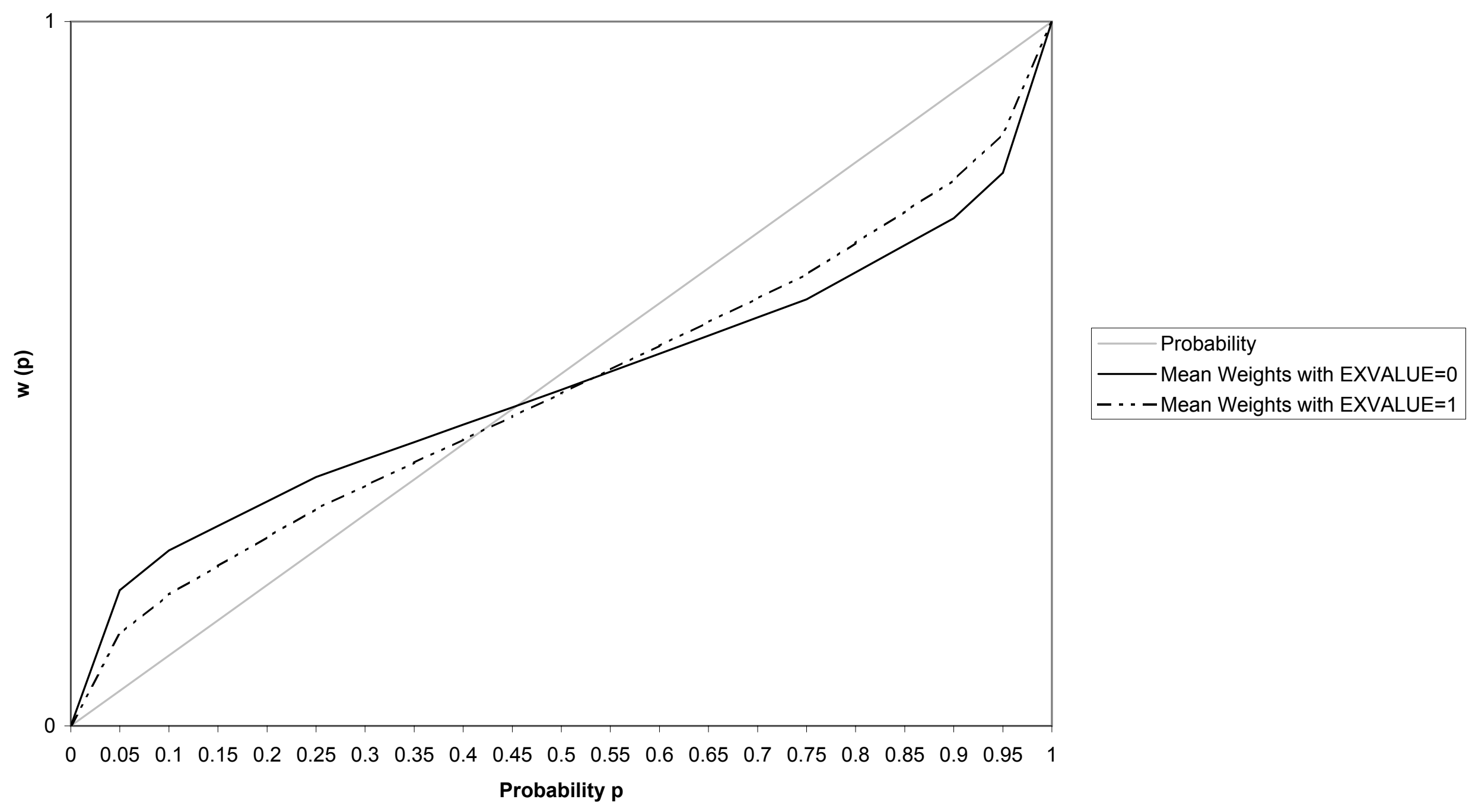




\section{Working Papers of the Center of Economic Research at ETH Zurich}

(PDF-files of the Working Papers can be downloaded at www.cer.ethz.ch/research.)

06/53 S. Valente

Trade, Envy and Growth: International Status Seeking in a Two-Country World

06/52 K. Pittel

A Kuznets Curve for Recycling

06/51 C.N. Brunnschweiler

Cursing the blessings? Natural resource abundance, institutions, and economic growth

06/50 C. Di Maria and S. Valente

The Direction of Technical Change in Capital-Resource Economies

06/49 C.N. Brunnschweiler

Financing the alternative: renewable energy in developing and transition countries

$06 / 48$ S. Valente

Notes on Habit Formation and Socially Optimal Growth

06/47 L. Bretschger

Energy Prices, Growth, and the Channels in Between: Theory and Evidence

06/46 M. Schularick and T.M. Steger

Does Financial Integration Spur Economic Growth? New Evidence from the First Era of Financial Globalization

05/45 U. von Arx

Principle guided investing: The use of negative screens and its implications for green investors

05/44 Ch. Bjørnskov, A. Dreher and J.A.V. Fischer

The bigger the better? Evidence of the effect of government size on life satisfaction around the world

05/43 L. Bretschger

Taxes, Mobile Capital, and Economic Dynamics in a Globalising World

05/42 S. Smulders, L. Bretschger and H. Egli

Economic Growth and the Diffusion of Clean Technologies: Explaining Environmental Kuznets Curves

05/41 S. Valente

Tax Policy and Human Capital Formation with Public Investment in Education

05/40 T. M. Steger and L. Bretschger

Globalization, the Volatility of Intermediate Goods Prices and Economic Growth

05/39 H. Egli

A New Approach to Pollution Modelling in Models of the Environmental Kuznets Curve

$05 / 38$ S. Valente

Genuine Dissaving and Optimal Growth

05/37 K. Pittel, J.-P. Amigues and T. Kuhn

Endogenous Growth and Recycling: A Material Balance Approach

05/36 L. Bretschger and K. Pittel

Innovative investments, natural resources, and intergenerational fairness: Are pension funds good for sustainable development?

04/35 T. Trimborn, K.-J. Koch and T.M. Steger

Multi-Dimensional Transitional Dynamics: A Simple Numerical Procedure

04/34 K. Pittel and D.T.G. Rübbelke 
Private Provision of Public Goods: Incentives for Donations

04/33 H. Egli and T.M. Steger

A Simple Dynamic Model of the Environmental Kuznets Curve

04/32 L. Bretschger and T.M. Steger

The Dynamics of Economic Integration: Theory and Policy

04/31 H. Fehr-Duda, M. de Gennaro, R. Schubert,

Gender, Financial Risk, and Probability Weights

03/30 T.M. Steger

Economic Growth and Sectoral Change under Resource Reallocation Costs

03/29 L. Bretschger

Natural resource scarcity and long-run development: central mechanisms when conditions are seemingly unfavourable

$03 / 28 \quad$ H. Egli

The Environmental Kuznets Curve - Evidence from Time Series Data for Germany

03/27 L. Bretschger

Economics of technological change and the natural environment: how effective are innovations as a remedy for resource scarcity?

03/26 L. Bretschger, S. Smulders

Sustainability and substitution of exhaustible natural resources. How resource prices affect long-term R\&D-investments

03/25 T.M. Steger

On the Mechanics of Economic Convergence

03/24 L. Bretschger

Growth in a Globalised Economy: The Effects of Capital Taxes and Tax Competition

02/23 M. Gysler, J.Kruse and R. Schubert

Ambiguity and Gender Differences in Financial Decision Making: An Experimental Examination of Competence and Confidence Effects

$01 / 22 \quad$ S. Rutz

Minimum Participation Rules and the Effectiveness of Multilateral Environmental Agremments

01/21 M. Gysler, M. Powell, R. Schubert

How to Predict Gender-Differences in Choice Under Risk: A Case for the Use of Formalized Models

00/20 S.Rutz, T. Borek

International Environmental Negotiation: Does Coalition Size Matter?

00/19 S. Dietz

Does an environmental Kuznets curve exist for biodiversity? 